\title{
Clinical Usefulness of Intraoperative Motor-Evoked Potential Monitoring during Temporal Lobe Epilepsy Surgery
}

\author{
Dae Lim Koo \\ Won Gu Lee ${ }^{\text {b }}$ \\ Seung-Chyul Hong ${ }^{c}$ \\ Dae-Won Seo ${ }^{d}$ \\ aDepartment of Neurology, \\ Boramae Medical Center, \\ Seoul National University \\ College of Medicine, Seoul, Korea \\ ${ }^{b}$ Department of Neurology, \\ Kosin University College of Medicine, \\ Busan, Korea \\ 'Departments of Neurosurgery and \\ ${ }^{\mathrm{d} N e u r o l o g y}$, Samsung Medical Center, \\ Sungkyunkwan University \\ School of Medicine, Seoul, Korea
}

Background and Purpose We aimed to determine the effectiveness of intraoperative neurophysiological monitoring focused on the transcranial motor-evoked potential (MEP) in patients with medically refractory temporal lobe epilepsy (TLE).

Methods We compared postoperative neurological deficits in patients who underwent TLE surgery with or without transcranial MEPs combined with somatosensory evoked potential (SSEP) monitoring between January 1995 and June 2018. Transcranial motor stimulation was performed using subdermal electrodes, and MEP responses were recorded in the four extremity muscles. A decrease of more than $50 \%$ in the MEP or the SSEP amplitudes compared with baseline was used as a warning criterion.

Results In the TLE surgery group without MEP monitoring, postoperative permanent motor deficits newly developed in 7 of 613 patients. In contrast, no permanent motor deficit occurred in 279 patients who received transcranial MEP and SSEP monitoring. Ten patients who exhibited decreases of more than 50\% in the MEP amplitude recovered completely, although two cases showed transient motor deficits that recovered within 3 months postoperatively.

Conclusions Intraoperative transcranial MEP monitoring during TLE surgery allowed the prompt detection and appropriate correction of injuries to the motor nervous system or ischemic stroke. Intraoperative transcranial MEP monitoring is a reliable modality for minimizing motor deficits in TLE surgery.

Key Words temporal lobe epilepsy, intraoperative monitoring, motor-evoked potentials.
Received October 4, 2018

Revised December 12, 2018

Accepted December 17, 2018

\section{Correspondence}

Dae-Won Seo, MD, $\mathrm{PhD}$

Department of Neurology,

Samsung Medical Center,

Sungkyunkwan University

School of Medicine,

81 Irwon-ro, Gangnam-gu,

Seoul 06351, Korea

Tel $+82-2-3410-3595$

Fax +82-2-3410-0052

E-mail daewon@skku.edu

\section{INTRODUCTION}

Temporal lobe epilepsy (TLE) is one of the most common types of medically refractory epilepsy. Epilepsy surgery offers the opportunity to maximize seizure freedom as well as prevent untimely death. Developments in neuroimaging and surgical techniques have improved surgical treatments for epilepsy. ${ }^{1-4}$ In medically refractory TLE, surgery is considered superior to prolonged medical therapy, especially in terms of seizure freedom and quality of life. ${ }^{1}$ Anterior temporal lobectomy with or without amygdalohippocampectomy is considered a standard surgical technique in patients with medically refractory TLE. Despite advancements in surgical procedures, a risk of neurological deficits during or after epilepsy surgery remains. Resective surgery for TLE has risks of surgical, neurological, neurocognitive, and psychological complications. ${ }^{5}$ Therefore, controlling seizures and minimizing neurological deficits are equally important issues.

Intraoperative neurophysiological monitoring (INM) has been adopted recently as a mandatory procedure during neurosurgery aimed at avoiding irreversible neurological deficits during surgery. Transcranial motor-evoked potential (MEP) monitoring is widely ap-

(®) This is an Open Access article distributed under the terms of the Creative Commons Attribution Non-Commercial License (https://creativecommons.org/licenses/by-nc/4.0) which permits unrestricted non-commercial use, distribution, and reproduction in any medium, provided the original work is properly cited. 
plied in brain or spine surgery to prevent potential injuries to the pyramidal motor system. ${ }^{6-10}$ Although the surgical field of TLE surgery is mainly restricted to the temporal lobe, which is far from motor tracts, one study found that $1.7 \%$ of anterior temporal lobectomies produced motor deficits such as hemiparesis or hemiplegia. ${ }^{11}$ However, the usefulness of INM during TLE surgery remains unclear. We aimed to compare the surgical outcomes and the utility of INM in patients who underwent TLE surgery with or without INM.

\section{METHODS}

This study included 892 patients who underwent TLE surgery performed consecutively by the epilepsy surgery team at Samsung Medical Center from January 1995 to June 2018. The patients were divided into 2 groups: the 613 patients in the control group without MEP monitoring were enrolled between January 1995 and December 2008, and the 279 patients in the MEP monitoring group were prospectively enrolled between January 2009 and June 2018. We evaluated motor deficits in both groups of patients. We employed both transcranial MEP and somatosensory evoked potential (SSEP) monitoring as standard intraoperative techniques in TLE surgery. Approval for this study was obtained from the Institutional Review Board at Samsung Medical Center (IRB No. 201512-007). We also obtained written informed consent from each patient or his/her legal representative for participation in this study.

\section{INM setting: MEP and SSEP monitoring}

General anesthesia was induced and maintained by the continuous infusion of propofol, vecuronium, and remifentanil. The infusion rate of vecuronium was controlled by train-offour technique (TOF). Two responses of abductor pollicis brevis muscles to $2 \mathrm{~Hz}$ median nerve stimuli in TOF were considered enough for MEP monitoring. Transcranial motor constant-voltage stimulation was performed using subdermal electrodes placed at the $\mathrm{C} 3$ and $\mathrm{C} 4$ positions. MEP responses were recorded bilaterally in upper extremity muscles (abductor pollicis brevis and abductor digiti minimi) and lower extremity muscles (tibialis anterior and abductor hallucis). The stimulation protocol for evoking MEPs comprised five 400 -volt pulses with durations of 50 to $200 \mu$ s, anodal stimulation, and a 2-ms interpulse interval applied to the hand and leg. The combinations of five pulses evoked small electromyographic responses in both extremities simultaneously. MEP waveforms were recorded intermittently over 5- to 30-min intervals. Electrodes for SSEP stimulation were placed bilaterally at the level of the wrist for the median nerve and the ankle for the posterior tibial nerve.
Recording electrodes were placed bilaterally at three levels: the popliteal fossa, cervical spine (C5), and vertex. The right and left posterior tibial nerves were stimulated at the ankle to obtain an averaged waveform that was repeated every $5 \mathrm{~min}$ continuously throughout the surgical procedure.

Baseline MEP and SSEP recordings were made before the start of the surgical procedure, and all subsequent recordings were superimposed and compared with these baseline recordings. A decrease of more than 50\% in the MEP or SSEP amplitude compared with the baseline data was used as a warning criterion. When the amplitude of the MEP or SSEP decreased, the following actions to correct the INM alteration were taken immediately: release of cerebral retraction, blood pressure elevation, irrigation with warm saline, application of papaverine or nimodipine to relieve vasospasm, and reconsideration of the current surgical step or surgical strategy. To estimate the accuracy of MEP and SSEP monitoring in epilepsy surgery, we calculated the sensitivity, specificity, positive predictive value (PPV), and negative predictive value (NPV) of each significant change in MEP and SSEP.

\section{Surgical procedures for TLE}

All patients with refractory TLE underwent anterior temporal lobectomy with tailored mesial temporal resection by a neurosurgeon (S.C.H.). ${ }^{1}$ The mesial temporal resection included the amygdala and hippocampus. ${ }^{12}$ Electrocorticography (ECoG) was applied after the anterior temporal lobe had been surgically resected. An additional tailored resection was performed whenever ECoG of the hippocampus or parahippocampal gyrus revealed interictal or ictal epileptiform discharges. The surgical procedures and perioperative complications were evaluated, and any perioperative changes were recorded. The epileptologists (neurologists and neurosurgeon) treated all of the patients postoperatively with the same antiepileptic drugs during the first postoperative year, including those who were free of seizures.

\section{Statistical analysis}

The clinical demographics and outcomes were compared between groups using the Mann-Whitney U test for continuous variables and Fisher's exact test for categorical variables. All of the continuous quantitative variables are presented as mean \pm standard-deviation values. All analyses were performed with the SPSS statistical software (version 19.0, IBM Corporation, Armonk, NY, USA). Probability ( $p$ ) values less than 0.05 were considered indicative of statistical significance.

\section{RESULTS}

The 613 included patients with TLE underwent epilepsy 
Table 1. Complications of TLE surgery before INM

\begin{tabular}{|c|c|c|c|c|c|c|c|c|}
\hline $\begin{array}{c}\text { Case } \\
\text { no. }\end{array}$ & $\begin{array}{c}\text { Sex/age, } \\
\text { years }\end{array}$ & $\begin{array}{c}\text { Epilepsy } \\
\text { classification }\end{array}$ & MRI findings & Location & $\begin{array}{l}\text { Epilepsy } \\
\text { Surgery }\end{array}$ & $\begin{array}{l}\text { Preoperative } \\
\text { motor status }\end{array}$ & $\begin{array}{l}\text { Postoperative } \\
\text { motor status }{ }^{*}\end{array}$ & $\begin{array}{l}\text { Postoperative } \\
\text { CT or MRI finding }\end{array}$ \\
\hline 1 & $\mathrm{~F} / 47$ & TLE & Hippocampal sclerosis & Left & $A T L+A H$ & Normal & $\begin{array}{l}\text { Right hemiparesis } \\
\text { (upper 3, lower 4+) }\end{array}$ & $\begin{array}{l}\text { Left basal ganglia } \\
\text { infarction }\end{array}$ \\
\hline 2 & $F / 29$ & TLE & Hippocampal sclerosis & Right & $A T L+A H$ & Normal & $\begin{array}{l}\text { Left arm monoparesis } \\
\text { (upper 4+) }\end{array}$ & $\begin{array}{l}\text { Right caudate nucleus } \\
\text { infarction }\end{array}$ \\
\hline 3 & $F / 26$ & TLE & Hippocampal sclerosis & Right & $\mathrm{ATL}+\mathrm{AH}$ & Normal & $\begin{array}{l}\text { Left hemiparesis } \\
\text { (upper } 1 / 2 \text {, lower } 1 / 2 \text { ) }\end{array}$ & $\begin{array}{l}\text { Right internal capsular } \\
\text { infarction }\end{array}$ \\
\hline 4 & $\mathrm{~F} / 44$ & TLE & Hippocampal sclerosis & Left & $\mathrm{ATL}+\mathrm{AH}$ & Normal & $\begin{array}{l}\text { Right hemiparesis } \\
\text { (upper 2, lower 4) }\end{array}$ & $\begin{array}{l}\text { Left internal capsular } \\
\text { infarction }\end{array}$ \\
\hline 5 & $\mathrm{~F} / 28$ & TLE & $\begin{array}{l}\text { Xanthoastrocytoma } \\
\text { with cortical dysplasia }\end{array}$ & Left & $A T L+A H$ & Normal & $\begin{array}{l}\text { Right hemiplegia } \\
\text { (upper 0, lower 0) }\end{array}$ & $\begin{array}{l}\text { Left basal ganglia } \\
\text { infarction }\end{array}$ \\
\hline 6 & $M / 32$ & TLE & Cavernous hemangioma & Right & $A T L+A H$ & Normal & $\begin{array}{l}\text { Left hemiparesis } \\
\text { (upper 4+, lower 4+) }\end{array}$ & No change \\
\hline 7 & $F / 27$ & TLE & Hippocampal sclerosis & Right & $A T L+A H$ & Normal & $\begin{array}{l}\text { Left hemiparesis } \\
\text { (upper 4-, lower 4-) }\end{array}$ & Right thalamic infarction \\
\hline
\end{tabular}

*Muscle power grading using the Medical Research Council scale.

AH: amygdalohippocampectomy, ATL: anterior temporal lobectomy, F: female, INM: intraoperative neurophysiological monitoring, M: male, TLE: temporal lobe epilepsy.

surgery before the application of transcranial MEP monitoring. Seven of the 613 cases (1.2\%) had newly identified permanent motor deficits. They were aged $33.3 \pm 8.6$ years (range: $26-47$ years), and $86 \%(n=6)$ of the patients were female. Anterior temporal lobectomy with amygdalohippocampectomy was performed in all patients. Four of the seven patients had hippocampal sclerosis, one had cavernous hemangioma, and one had xanthoastrocytoma with cortical dysplasia. There was no recovery from the motor deficits within 6 months postoperatively. One patient exhibited complete postoperative hemiplegia in her right extremities, which postoperative MRI revealed as being caused by a left basal ganglia infarction. Moderate-to-severe left hemiparesis (motor grade 1-3) was evident in three patients, while another three patients had mild hemiparesis (motor grade 4). The clinical characteristics of the subjects with postoperative neurological deficits are summarized in Table 1.

Epilepsy surgery with simultaneous INM was performed in 279 patients with TLE (Table 2). Ten of these individuals exhibited intraoperative MEP changes, with complete waveform loss in four patients and a decrease of more than 50\% in six (Figs. 1 and 2). The duration of the decreased MEP signals was $32.0 \pm 21.2 \mathrm{~min}$ despite applying immediate corrective actions. The MEP waveforms had recovered in all patients by the end of surgery. Cerebral retraction was the most common cause of the MEP changes ( $50 \%$ of cases), followed by cerebrospinal fluid (CSF) loss (30\%), low blood pressure (10\%), and vasospasm (10\%). The sensitivity, specificity, PPV, and NPV for intraoperative MEP monitoring were $100 \%$, $97.1 \%, 20 \%$, and $100 \%$, respectively. Two of the 10 patients
Table 2. Clinical characteristics of 279 patients in the TLE surgery group with INM

\begin{tabular}{lc}
\hline \multicolumn{1}{c}{ Characteristic } & Value \\
\hline Age, years & $32.6 \pm 9.9$ \\
Sex, male & $140(50.2)$ \\
Epilepsy classification & \\
\hline TLE & $279(100)$ \\
$\quad$ Right & $134(48.0)$ \\
$\quad$ Left & $145(52.0)$ \\
Etiology & \\
\hline Hippocampal sclerosis & $152(54.8)$ \\
Cavernous angioma & $37(13.3)$ \\
Glioma & $27(9.7)$ \\
\hline DNET & $18(6.5)$ \\
\hline Focal cortical dysplasia & $9(3.2)$ \\
AVM & $9(3.2)$ \\
\hline Unknown & $27(9.7)$ \\
\hline
\end{tabular}

Data are mean \pm standard-deviation or $n(\%)$ values.

AVM: arteriovenous malformation, DNET: dysembryoplastic neuroepithelial tumor, INM: intraoperative neurophysiological monitoring, TLE: temporal lobe epilepsy.

with significant MEP changes showed SSEP changes of more than $50 \%$, which completely recovered to baseline after irrigation with warm saline. The sensitivity, specificity, PPV, and NPV for intraoperative SSEP monitoring were $0 \%, 99.3 \%$, $0 \%$, and $99.3 \%$, respectively. Postoperative examinations of the motor status detected transient hemiparesis or monoparesis in the left upper extremity in two patients immediately after surgery (case numbers 2 and 9). The motor deficits recovered to the normal levels within 1 month after surgery. Two 


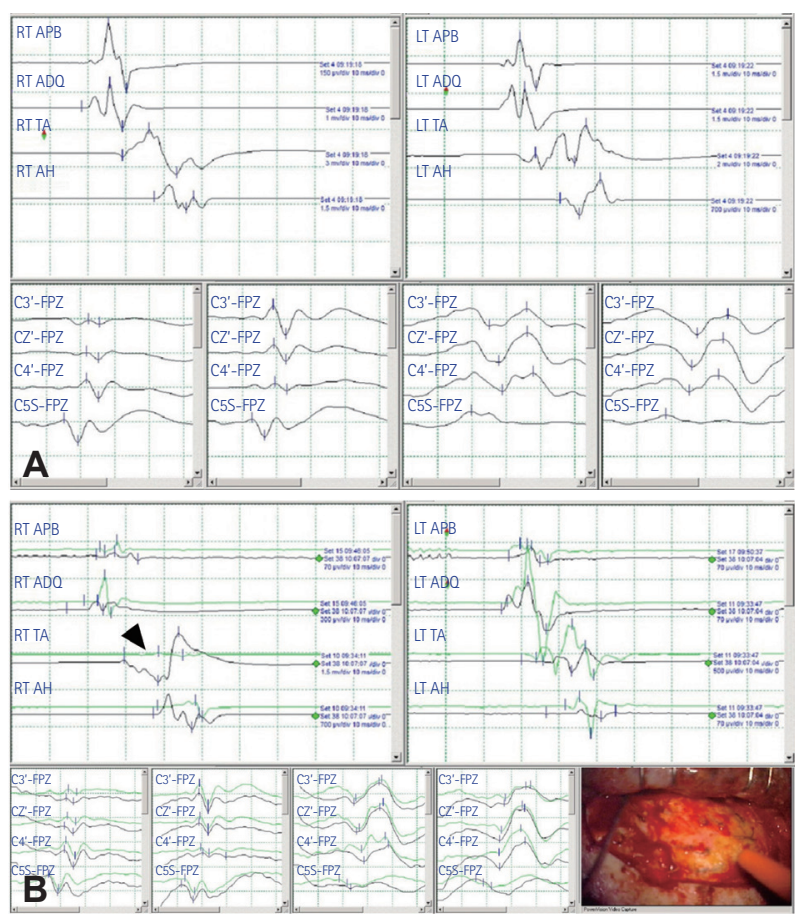

Fig. 1. MEP changes during epilepsy surgery in case 8 . A: The early waves of MEP and SSEP before craniectomy are shown. Left and right MEP are in upper panel. Left median, right median, left posterior tibial, and right posterior tibial nerve SSEP (from left to right) are in lower panel. Waves in green are real-time acquired data, while those in black are baseline one. B: In MEP monitoring, the waves in right lower extremity disappeared for 17 minutes during temporal lobe epilepsy surgery (arrowhead). No significant changes in SSEP occur throughout the operation. The photo shows the operative field in right ATL+AH. ADQ: abductor digiti quinti, AH: abductor halluces, APB: abductor pollicis brevis, ATL: anterior temporal lobectomy, LT: left, MEP: motor-evoked potential, RT: right, SSEP: somatosensory evoked potential, TA: tibialis anterior.

patients had minimal pneumocephalus on postoperative CT or MRI scans (case numbers 4 and 5), but no newly developed ischemic lesion was observed. The characteristics of the patients are summarized in Table 3 . The postoperative motor deficits in the monitored group were in 0 of $279 \mathrm{pa}-$ tients, while those in the non-monitored group were in 7 of 613 patients, even though that result did not reach statistical significance $(p=0.073)$.

\section{DISCUSSION}

This prospective observational study found that the clinical outcomes of patients who underwent TLE surgery were more favorable with MEP monitoring than without MEP monitoring. Immediate actions such as the release of cerebral retraction, irrigation with saline, and elevation of blood pressure were taken to restore MEP or SSEP waveforms when MEP changes occurred. These prompt corrective procedures might

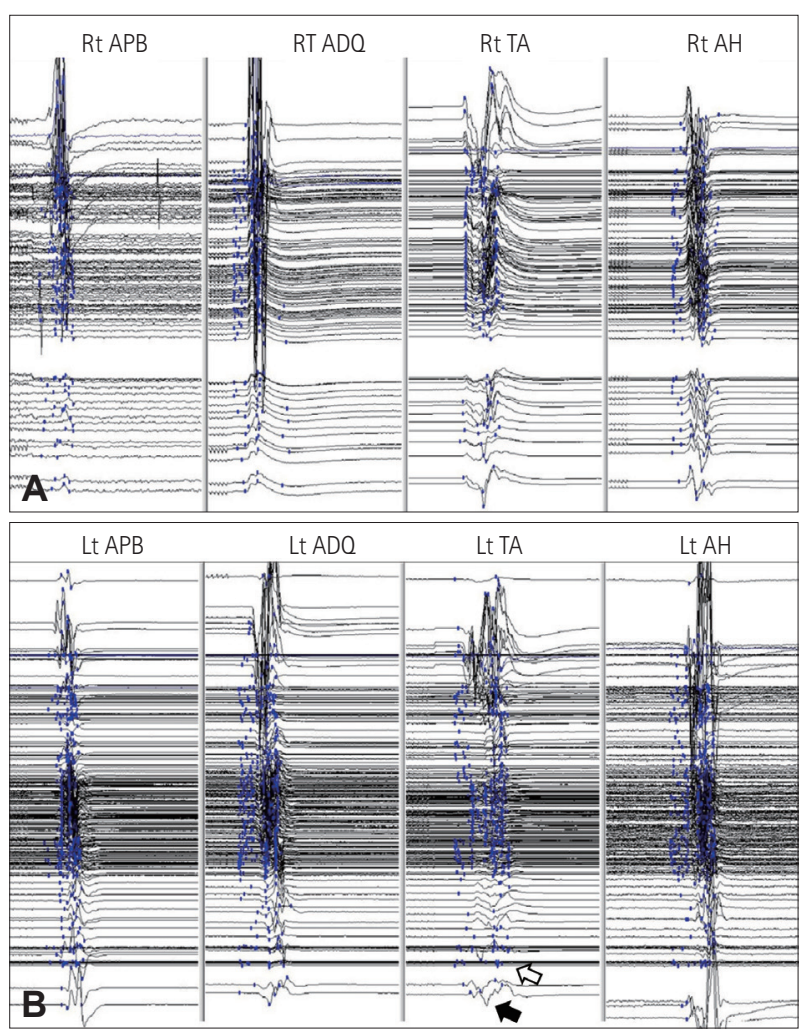

Fig. 2. Stack images of MEP changes during epilepsy surgery in case 8 . A: In left MEP monitoring, no significant wave changes of right upper and lower extremities are observed during the surgery. B: In right MEP monitoring, MEP disappears for 17 minutes (open arrow) and recovers after releasing cerebral retraction (closed arrow). ADQ: abductor digiti quinti, AH: abductor halluces, APB: abductor pollicis brevis, Lt: left, MEP: motor-evoked potential, Rt: right, TA: tibialis anterior.

have reduced permanent motor deficits in the MEP monitoring group. Injuries to the motor nervous system or ischemic stroke may occur during TLE surgery, although in our cases there was no direct intraoperative injury to the motor pathway. To the best of our knowledge, this is the first study to demonstrate that intraoperative MEP monitoring during TLE surgery is a reliable modality for preventing permanent motor deficits in patients with medically refractory TLE.

TLE is the most common form of focal epilepsy, and approximately one-third of patients suffering from seizures are eventually diagnosed with medically refractory epilepsy. ${ }^{13,14}$ In TLE, Wiebe et al. ${ }^{1}$ demonstrated that surgical treatment was superior to prolonged medical treatment in controlling seizures and improving the quality of life. Neurological complications after temporal lobe resective surgery include visual field deficits, hemianopsia, cranial nerve palsy, dysphasia/aphasia, and hemiparesis. ${ }^{5}$ Postoperative hemiparesis has been reported to develop in $1.8-5 \%$ of patients who undergo TLE surgery. ${ }^{11,15-17}$ In our study, $1.2 \%$ of patients without MEP monitoring showed permanent motor deficits including hemiparesis/hemiplegia after TLE surgery. 
Table 3. Summary of INM changes and postoperative outcomes in patients with INM

\begin{tabular}{|c|c|c|c|c|c|c|c|c|c|c|c|c|}
\hline $\begin{array}{l}\text { Case } \\
\text { no. }\end{array}$ & $\begin{array}{l}\text { Sex/ } \\
\text { age, } \\
\text { years }\end{array}$ & $\begin{array}{l}\text { Epilepsy } \\
\text { type }\end{array}$ & Side & $\begin{array}{l}\text { Epilepsy } \\
\text { surgery }\end{array}$ & $\begin{array}{l}\text { Preoperative } \\
\text { motor status }\end{array}$ & $\begin{array}{c}\text { Cause of MEP } \\
\text { changes }\end{array}$ & $\begin{array}{c}\text { MEP } \\
\text { changes }\end{array}$ & $\begin{array}{l}\text { Duration } \\
\text { of MEP } \\
\text { change, } \\
\text { min }\end{array}$ & $\begin{array}{l}\text { SSEP } \\
\text { changes }\end{array}$ & $\begin{array}{l}\text { Duration } \\
\text { of SSEP } \\
\text { change, } \\
\text { min }\end{array}$ & $\begin{array}{l}\text { Postoperative } \\
\text { motor status }\end{array}$ & $\begin{array}{c}\text { Postoperative } \\
\text { CT or MRI } \\
\text { finding }\end{array}$ \\
\hline 1 & $\mathrm{~F} / 42$ & TLE & Right & $\mathrm{ATL}+\mathrm{AH}$ & Normal & $\begin{array}{l}\text { Cerebral } \\
\text { retraction }\end{array}$ & Loss & 22 & No & - & Normal & None \\
\hline 2 & $M / 31$ & TLE & Right & $\mathrm{ATL}+\mathrm{AH}$ & Normal & $\begin{array}{l}\text { Low blood } \\
\text { pressure }\end{array}$ & Loss & 20 & No & 更 & $\begin{array}{l}\text { Left } \\
\text { hemiparesis } \\
\text { (transient) }\end{array}$ & None \\
\hline 3 & $\mathrm{M} / 30$ & TLE & Left & $\mathrm{ATL}+\mathrm{AH}$ & Normal & Brain shrinkage & $\begin{array}{c}\text { Decrease } \\
>50 \%\end{array}$ & 62 & $\begin{array}{c}\text { Decrease } \\
>50 \%\end{array}$ & 53 & Normal & None \\
\hline 4 & $\mathrm{M} / 18$ & TLE & Right & $A T L+A H$ & Normal & $\begin{array}{l}\text { Cerebral } \\
\text { retraction }\end{array}$ & $\begin{array}{c}\text { Decrease } \\
>50 \%\end{array}$ & 10 & No & - & Normal & $\begin{array}{l}\text { Minimal } \\
\text { pneumocepha- } \\
\text { lus }\end{array}$ \\
\hline 5 & $F / 29$ & TLE & Right & $A T L+A H$ & Normal & $\begin{array}{l}\text { Cerebral } \\
\text { retraction }\end{array}$ & $\begin{array}{c}\text { Decrease } \\
>50 \%\end{array}$ & 64 & No & - & Normal & $\begin{array}{l}\text { Minimal } \\
\text { pneumocepha- } \\
\text { lus }\end{array}$ \\
\hline 6 & $F / 14$ & TLE & Left & $A T L+A H$ & Normal & $\begin{array}{l}\text { Cerebral } \\
\text { retraction }\end{array}$ & $\begin{array}{c}\text { Decrease } \\
>50 \%\end{array}$ & 15 & No & - & Normal & None \\
\hline 7 & $\mathrm{~F} / 30$ & TLE & Left & $A T L+A H$ & Normal & Brain shrinkage & $\begin{array}{c}\text { Decrease } \\
>50 \%\end{array}$ & 26 & No & - & Normal & None \\
\hline 8 & $\mathrm{~F} / 44$ & TLE & Right & $A T L+A H$ & Normal & $\begin{array}{l}\text { Cerebral } \\
\text { retraction }\end{array}$ & Loss & 17 & No & - & Normal & None \\
\hline 9 & $\mathrm{~F} / 40$ & TLE & Right & $A T L+A H$ & Normal & $\begin{array}{c}\text { Intraoperative } \\
\text { vasospasm }\end{array}$ & $\begin{array}{c}\text { Decrease } \\
>50 \%\end{array}$ & 60 & No & 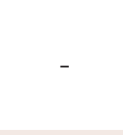 & $\begin{array}{l}\text { Left arm } \\
\text { monoparesis } \\
\text { (transient) }\end{array}$ & None \\
\hline 10 & $M / 33$ & TLE & Right & $\mathrm{ATL}+\mathrm{AH}$ & Normal & Brain shrinkage & Loss & 24 & $\begin{array}{c}\text { Decrease } \\
>50 \%\end{array}$ & 12 & Normal & None \\
\hline
\end{tabular}

AH: abductor halluces, ATL: anterior temporal lobectomy, INM: intraoperative neurophysiological monitoring, MEP: motor-evoked potentials, SSEP: somatosensory evoked potentials, TLE: temporal lobe epilepsy.

Intraoperative monitoring of transcranial MEP is a wellestablished method for predicting postoperative motor deficits during surgery for intracranial lesions. ${ }^{18,19}$ Specifically, if an intracranial lesion is located around the motor cortex or pathway, transcranial MEP monitoring becomes more important. The risk of postoperative motor deficits might be lower for TLE surgery than for motor tract surgery due to the separation between the temporal resective area and the motor pathway. However, perioperative motor deficits can occur due to several confounding factors during TLE surgery. Cerebral retraction has been considered one of the causes of decreased MEPs during brain surgery. Brain edema, vascular compromise causing ischemia, and direct damage to the surrounding cortex can result from cerebral retraction. ${ }^{20}$ Our laboratory considers a decrease in amplitude of more than $50 \%$ as an "alarm sign" during brain surgery. ${ }^{10}$ Cerebral retraction was the most common cause of transcranial MEP signal decreases of more than 50\% that occurred in 10 (50\%) of the present patients. These changes completely recovered to baseline after the cerebral retraction was relieved. MEP signals can change during intraoperative monitoring without any direct damage to the motor pathway. ${ }^{21}$ Several of the present cases showed gradual and persistent MEP decreases or increases despite the prompt correction of the cause of MEP changes. Gradual and persistent MEP changes might be associated with indirect injury to the motor pathway and systemic factors such as inadequate blood pressure, temperature, and anesthetic agents. Furthermore, the significant MEP changes in our patients without postoperative motor deficits might have represented false-positive MEP findings. A recent study found that pneumocephalus was associated with an increase in the threshold stimulus intensity during intraoperative MEP monitoring when there was no damage to the motor pathway. ${ }^{22}$ In our study, postoperative CT or MRI scans revealed minimal pneumocephalus in $20 \%$ of patients with decreases in MEP. Pneumocephalus is known to develop after dural opening mainly due to the loss of CSF caused by the opening of the subarachnoid space. Two pa- 
tients in our surgery group with INM monitoring showed decreases of more than 50\% in the SSEP amplitude that were accompanied by significant MEP changes, which returned to baseline after saline irrigation and dural closure. Based on our TLE surgical outcomes with intraoperative monitoring, MEP monitoring was more useful than SSEP monitoring for avoiding neurological deficits. Our data have provided evidence for the usefulness of MEP monitoring in patients who undergo TLE surgery, but further studies are needed to corroborate our findings.

Before the application of intraoperative monitoring, seven $(1.2 \%)$ of the cases had irreversible hemiplegia or hemiparesis despite TLE surgery being performed far from the motor tract. The application of intraoperative monitoring provided the surgeon with real-time feedback about the risk of neurological deficit during surgery. Ten of the 279 patients with intraoperative monitoring (3.6\%) showed significant MEP changes in the risk of a neurological deficit, but immediate responses from the intraoperative monitoring team resulted in no permanent neurological deficit in any of the cases. Intraoperative monitoring could contribute to better surgical outcomes because permanent deficits developed in six $(86 \%)$ cases after a learning period for the surgical procedures of more than 7 years. Our data on intraoperative MEP monitoring have revealed greater sensitivity, specificity, and NPV for postoperative neurological deficits compared to intraoperative SSEP monitoring. As a limitation of our study, other intraoperative modalities such as visual evoked potentials and brainstem auditory evoked potentials were not monitored routinely. The usefulness of applying multimodal INM in TLE surgery needs to be investigated in future studies.

The safety of the transcranial electrical stimulation procedure used in MEP monitoring has been established. ${ }^{23,24}$ According to the guideline of the American Clinical Neurophysiology Society (ACNS) ${ }^{24}$ transcranial MEP can induce seizures, but their reported incidence has been very low, with 1 study finding only 5 seizures in more than 15,000 operations during MEP monitoring. The ACNS recommended that a history of epilepsy should not been considered a contraindication to MEP stimulation. However, the transcranial electrical stimuli did not provoke any epileptic seizure in our 279 patients. This absence of seizures might have been due to several factors. First, our patients with epilepsy have been still on antiepileptic drugs during the surgery. Second, the general anesthetics might enhance the seizure threshold. Third, the epileptogenic zone of our patients with TLE was distant from the location of transcranial MEP stimulation, which was around the suprasylvian central area.

In conclusion, transcranial MEP monitoring in patients with TLE resulted in the prompt detection and appropriate correction of motor deficits during surgery. Intraoperative MEP monitoring should be performed to prevent or minimize the occurrence of postoperative motor deficits in TLE surgery. This study highlights the need for further research to determine the necessity of transcranial MEP monitoring in surgical candidates with medically refractory TLE.

\section{Conflicts of Interest}

The authors have no financial conflicts of interest.

\section{Acknowledgements}

This research was supported by Samsung Medical Center grant (\#SMX117 0221).

\section{REFERENCES}

1. Wiebe S, Blume WT, Girvin JP, Eliasziw M; Effectiveness and Efficiency of Surgery for Temporal Lobe Epilepsy Study Group. A randomized, controlled trial of surgery for temporal-lobe epilepsy. $N$ Engl J Med 2001;345:311-318.

2. Engel J Jr. The timing of surgical intervention for mesial temporal lobe epilepsy: a plan for a randomized clinical trial. Arch Neurol 1999;56: 1338-1341.

3. Al-Otaibi F, Baeesa SS, Parrent AG, Girvin JP, Steven D. Surgical techniques for the treatment of temporal lobe epilepsy. Epilepsy Res Treat 2012;2012:374848.

4. Muzumdar D, Patil M, Goel A, Ravat S, Sawant N, Shah U. Mesial temporal lobe epilepsy-An overview of surgical techniques. Int J Surg 2016;36:411-419.

5. Georgiadis I, Kapsalaki EZ, Fountas KN. Temporal lobe resective surgery for medically intractable epilepsy: a review of complications and side effects. Epilepsy Res Treat 2013;2013:752195.

6. Kim SM, Kim SH, Seo DW, Lee KW. Intraoperative neurophysiologic monitoring: basic principles and recent update. J Korean Med Sci 2013; 28:1261-1269.

7. Ichikawa T, Suzuki K, Sasaki T, Matsumoto M, Sakuma J, Oinuma M, et al. Utility and the limit of motor evoked potential monitoring for preventing complications in surgery for cerebral arteriovenous malformation. Neurosurgery 2010;67(3 Suppl Operative):ons222-ons228.

8. Maruta Y, Fujii M, Imoto H, Nomura S, Tanaka N, Inamura A, et al. Strategies and pitfalls of motor-evoked potential monitoring during supratentorial aneurysm surgery. J Stroke Cerebrovasc Dis 2016;25:484495.

9. Neuloh G, Pechstein U, Cedzich C, Schramm J. Motor evoked potential monitoring with supratentorial surgery. Neurosurgery 2007;61(1 Suppl):337-346

10. Szelényi A, Hattingen E, Weidauer S, Seifert V, Ziemann U. Intraoperative motor evoked potential alteration in intracranial tumor surgery and its relation to signal alteration in postoperative magnetic resonance imaging. Neurosurgery 2010;67:302-313.

11. Mathon B, Navarro V, Bielle F, Nguyen-Michel VH, Carpentier A, Baulac M, et al. Complications after surgery for mesial temporal lobe epilepsy associated with hippocampal sclerosis. World Neurosurg 2017; 102:639-650.e2.

12. Girvin JP. Resection of intracranial lesions under local anesthesia. Int Anesthesiol Clin 1986;24:133-155.

13. Schuele SU, Lüders HO. Intractable epilepsy: management and therapeutic alternatives. Lancet Neurol 2008;7:514-524.

14. Spencer S, Huh L. Outcomes of epilepsy surgery in adults and children. Lancet Neurol 2008;7:525-537.

15. Erba G, Winston KR, Adler JR, Welch K, Ziegler R, Hornig GW. Temporal lobectomy for complex partial seizures that began in childhood. Surg Neurol 1992;38:424-432. 
Brain retraction injury. Neurol Res 2003;25:831-838.

21. Lyon R, Feiner J, Lieberman JA. Progressive suppression of motor evoked potentials during general anesthesia: the phenomenon of "anesthetic fade." J Neurosurg Anesthesiol 2005;17:13-19.

22. Abboud T, Huckhagel T, Stork JH, Hamel W, Schwarz C, Vettorazzi E, et al. Why does threshold level change in transcranial motor-evoked potentials during surgery for supratentorial lesions? J Neurosurg Anesthesiol 2017;29:393-399.

23. MacDonald DB. Safety of intraoperative transcranial electrical stimulation motor evoked potential monitoring. J Clin Neurophysiol 2002; 19:416-429.

24. Legatt AD, Emerson RG, Epstein CM, MacDonald DB, Deletis V, Bravo RJ, et al. ACNS guideline: transcranial electrical stimulation motor evoked potential monitoring. J Clin Neurophysiol 2016;33:42-50. 